\title{
ANAK-ANAK PANTAI PURUS DI TENGAH ARUS 4.0
}

\author{
Azmi Fitrisia \\ Email: azmifitrisia@fis.unp.ac.id \\ Jurusan Sejarah Universitas Negeri Padang
}

\begin{abstract}
Abstrak
Kemajuan teknologi informasi telah memasuki semua lini kehidupan. Tidak terjadi lagi perbedaan antara masyarakat perkotaan dengan masyarakat yang tinggal di kawasan pedesaan. Demikian pula perbedaan yang kabur antara penduduk yang menetap di kawasan pantai dan kawasan daratan. Dimana ada sinyal maka polanya akan cendrung sama. Hal ini tentu menarik karena homogenitas akan berlaku dalam kehidupan masyarakat. Padahal sosio-budaya, pendidikan dan ekonomi tiap-tiap masyarakat sangatlah beragam. Tulisan ini ingin membuktikan hal ini pada anak-anak di kawasan pantai Purus. Bagaimana perubahan yang terjadi pada anakanak di kawasan pantai di tengah arus 4.0. Permasalahannya selama ini telah terbangun stereotip yang menyatakan bahwa anak anak yang tinggal di kawasan pantai cendrung nakal, kasar dan keras. Mereka banyak tidak bersekolah. Hasil penelitian ini membuktikan bahwa anak-anak di pantai Purus yang berada di Kelurahan Purus belum mampu mengembangkan diri dengan kemajuan teknologi 4.0. Sebaliknya sebahagian dari mereka semakin terpengaruh dan terpasung dalam fantastisme dunia maya. Ada ketakutan anak-anak Purus semakin terpinggirkan kelak. Hal ini karena tingkat ekonomi yang lemah dan rendahnya pendidikan. Demkian pula kesadaran orangtua akan pentingnya masa depan dengan pendidikan juga kurang. Padahal teknologi canggih menuntut keahlian dengan tingkat pendidikan yang relatif tinggi.
\end{abstract}

Keyword: Anak-anak pantai, Purus, arus 4.0

\section{Pendahuluan}

Perhatian terhadap masyarakat pedesaan dan pantai Indonesia sudah mulai dicurahkan Sayagyo dan Pujiati Sayogyo, ${ }^{1}$ Mubyarto dan kawan kawan, ${ }^{2}$ Kusnadi $^{3}$, Mulyadi. $S^{4}$, Dian Saptarini dkk ${ }^{5}$, Ahmad Fauzi $^{6}$, Elfindri ${ }^{7}$ Arif Sritua ${ }^{8}$, Pudji Purwanti ${ }^{9}$. Namun karya diatas kurang menyinggung anak-anak

${ }^{1}$ Sajogyo dan Pujiwati Sajogyo, ed. Sosiologi Pedesaan. Yogyakarta: Gadjahmada University Press, 1983.

${ }^{2}$ Mubyarto dan Kawan Kawan, Kemiskinan pada Masyarakat di Dua Desa Pantai. Jakarta: Sinar Harapan, 1984.

${ }^{3}$ Kusnadi, Akar Kemiskinan Nelayan. Yogyakarta: LKiS, 2003.

${ }^{4}$ Mulyadi.S, Ekonomi Kelautan. Jakarta: Rajagrafindo Persada, 2005.

5 Dian Saptarini, Suprapti, Happy Ratna Santosa, Pengelolaan Sumberdaya Kelautan dan Wilayah Pesisir. Jakarta: 1996.

${ }^{6}$ Ahmad Fauzi, Ekonomi Perikanan:Teori Kebijakan dan Pengelolaan. Jakarta:Gramedia Pustaka Utaa,

2010

${ }^{7}$ Elfindri, Ekonomi Patron -Client: Fenomena Mikro Rumah Tangga Nelayan dan Kebijakan Makro. Padang: Universitas Andals Press 2002

${ }^{8}$ Arif Sritua, Pengantar Sosiologi Masyarakat Pesisir. Jakarta: Kerjasana Ekologi Manusia IPB dengan Yayasan Pustaka Obor Indonesia, 2015.

162 | Seminar Nasional Sejarah ke 4 Jurusan Pendidikan Sejarah Universitas Negeri Padang 
nelayan. Beberapa artikel pada jurnal telah ditulis M. Zauwir Abdullah, Tri Sukirno Putro dan Syapsan ${ }^{10}$ Nani Suryani, Siti Amanah, Yatri Indah Kusumastuti. ${ }^{11}$ Nina Siti Salmaniah Siregar ${ }^{12}$ namun tidak berkaitan arus revolusi industri 4.0 terhadap anak anak di kawasan pantai. Ketiga artikel diatas lebih menyoroti pendidikan anak nelayan karena permasalahan sosial ekonomi orang tua dan kurangnya kesadaran orang tua pentingnya pendidikan. Fenomena 4.0 telah berpengaruh diberbagai sektor termasuk sektor kelautan dan perikanan ${ }^{13}$ Anak-anak nelayan generasi masa depan perlu mendapat perhatian. Lebih lagi karena secara geografis dua pertiga wilayah Indonesia adalah perairan. Mereka yang dekat dan inheren dengan laut serta kawasan pesisir seperti anak-anak nelayan adalah aset terdepan dalam sektor kemaritiman bangsa. Merekalah lapisan pertama untuk perlindungan dan pengelolaan laut dan pesisir. Namun apabila ternyata anak-anak pantai ini berpendidikan rendah atau anak-anak tersebut rusak mental dan tidak menjadi insan yang baik maka akan bagaimana? Permasalahan artikel ini adalah bagaimana kondisi anak anak nelayan Kelurahan Purus dalam arus 4.0? Bagaimanakah tindakan yang sudah dilakukan untuk mengantisipasi permasalahan yang terjadi?

\section{Metodologi}

${ }^{9}$ Pudji Purwanti, Model Ekonomi Rumah Tangga Nelayan Skala Kecil. Malang: Universitas Brawijaya Press, 2010.

${ }^{10}$ M. Zauwir Abdullah, Tri Sukirno Putro dan Syapsan, Pengaruh Kondisi Sosial Ekonomi terhadap Tingkat Pendidikan Anak-Anak Nelayan Kecamatan Mandah Kabupaten Indragiri Hilir, dalam jurnal Ekonomi Vol 25 No. 3, September 2017.

11 Nani Suryani, Siti Amanah, Yatri Indah Kusumastuti, Analisis Pendidikan Formal Anak pada Keluarga Nelayan Di Desa Kalangjaladri Kecamatan Parigi Kabupaten Ciamis Provinsi Jawa Barat. Dalam Buletin Ekonomi Perikanan. Vol. 5. No. 2, 2004

${ }^{12}$ Nina Siti Salmaniah Siregar, Kesadaran Masyarakat Nelayan terhadap Pendidikan Anak. Dalam Jurnal Ilmu Pemerintahan dan Sosial Politik, Vol 4 No.1, 2016. hlm 1-10.

13 Alreza Rizky Fauzi, Revolusi Industri 4.0 di Sektor Maritim ASEAN, dalam https://medium.com/@kastrat.himatekpal/revolusi-industri-4-0-di-sektor-mari

tim-asean-bb15b76d30ae. Diakses 1 Agustus 2019. Manfaatkan Era Industri 4.0 untuk Pembangunan Perikanan Budidaya dalam https://www.tokohkita.co/read/2019

0214/187/manfaatkan-era-industri-40-untuk-pembangunan-perikanan-budid. Diakses 1 Agustus 2019. Lihat juga "Telkomsat Berpartisipasi dalam Seminar Nasional "Nela yan Indonesia Berdaulat Melalui Teknologi 4.0” dalam https://www.telkomsat.co.Id/

id/berita/telkomsat-berpartisipasi-dalam-seminar-na. Daikases 1 Agustus 2019 
Pendekatan sejarah sosial menjadi sudut pandang kajian ini, terutama sejarah sosial anak-anak pantai. Pemahaman anak-anak pantai adalah anak-anak dari penduduk yang tinggal di tepi laut dengan kebergaman mata pencaharian. Mereka berusia antara 6-20 tahun. Anak anak pantai dibedakan anak anak petani sebagaimana perbedaan pekerjaan sebagai petani dengan nelayan. ${ }^{14}$ Secara umum tergolong masyarakat yang tinggal disepanjang pantai. Mereka dibedakan berdasarkan klasifikasi sebagai masyarakat kaya, menengah dan miskin. Indikator untuk klasifikasi sangat bergantung pada kepemilikan. Pada sisi lain pemerintah juga melakukan klasifikasi atas ekonomi masyarakat seperti prasejahtera, sejahtera I dll. Kajian ini akan mencoba memahami anak-anak dari golongan menengah kebawah. Satu yang terpenting dan tidak mungkin diabaikan adalah arah dan tujuan perkembangan masyarakat. Konsep manusia seutuhnya milik Mubyarto dan kawan-kawan sangat relevan. ${ }^{15}$ Selarinya arus 4.0 mendukung kemajuan masyarakat terutama anak-anak pantai. Melalui arus 4.0 anak-anak pantai terbuka pemikiran untuk berhasil berbanding kemunduran.

Pengaruh akan diamati dan dikaji secara kualitatif. Selain itu akan digunakan sumber primer dan sekunder bagi kajian ini. Pengumpulan data tertulis dari kantor Kelurahan Purus, dan perpustakaan. Observasi dan wawancara dilakukan untuk mendapatkan data. Data yang diperoleh dikritik dan seterusnya diinterpretasikan membangun satu kesatuan dalam penulisan.

\section{Tantatagan Anak-Anak Pantai Purus}

Kelurahan Purus yang terdapat pada Kecamatan Padang Barat Kota Padang merupakan kawasan pantai. Kelurahan Purus dibagi atas Purus I,II, II dan IV dengan 8 RW. Sebelah Utara Kelurahan Purus berbatasan dengan Kelurahan Rimbo Kaluang.

${ }^{14}$ Raymond Firth, Malay Fishermen Their Peasent Economy. New York : W.E. Norton \& Company. INC, 1975, hlm .22

${ }^{15}$ Mubyarto dkk, Nelayan dan Kemiskinan Studi Ekonomi Antropologi di Dua Desa Pantai. Jakarta: CV rajawali, 1984, hlm.8.

164 | Seminar Nasional Sejarah ke 4 Jurusan Pendidikan Sejarah Universitas Negeri Padang 
Peta Kelurahan Purus Kecamatan Pdang Barat Kota Padang
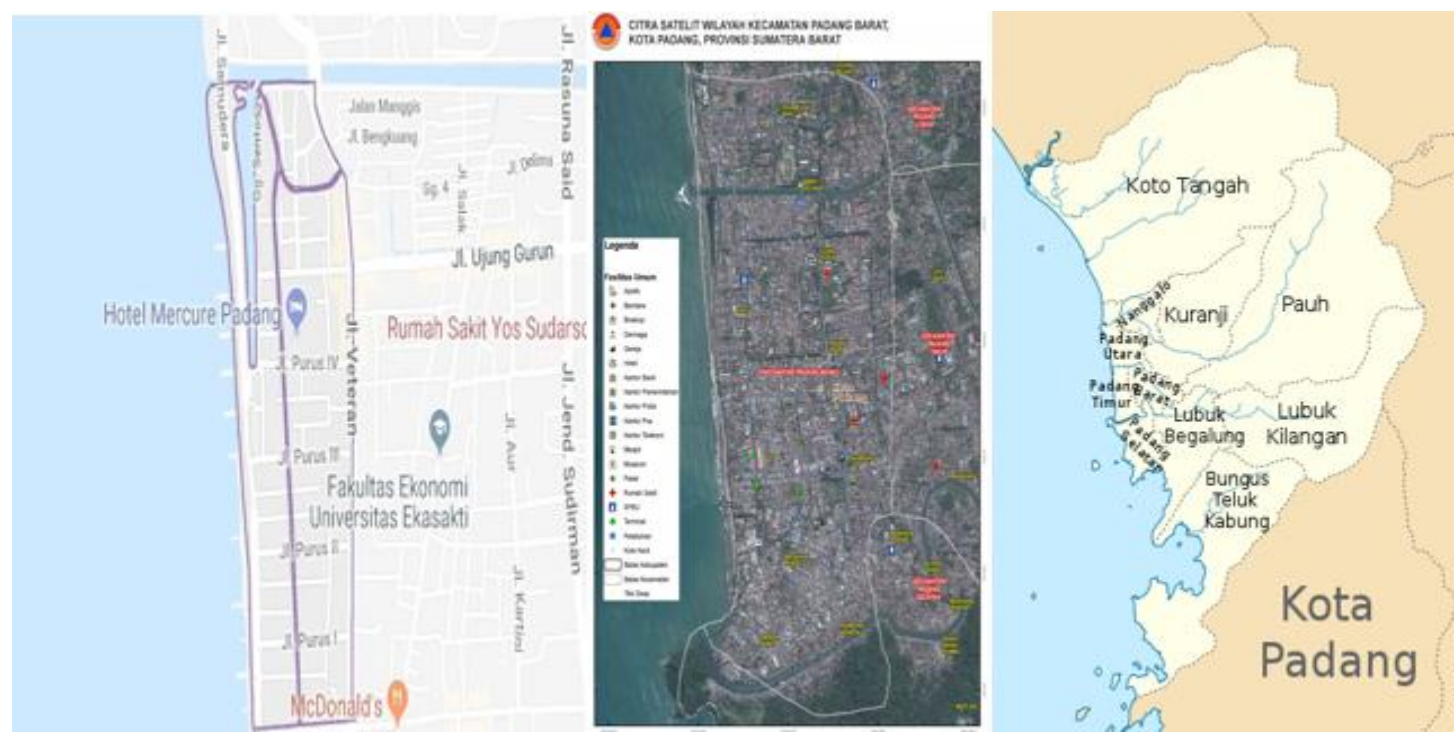

Sumber: http://geospasial.bnpb.go.id/2009/10/05/citra-satelit-wilayahhttps://www.google.com/search?q=PETA+KOTA+PADANG\&safe

Sebelah Selatan berbatasan dengan Kelurahan Olo, Sebelah Timur berbatasan dengan Kelurahan Padang Pasir dan sebelah Barat berbatasan dengan Samudera Indonesia. ${ }^{16}$ Kelurahan ini berjarak sekitar $1 \mathrm{~km}$ dari ibukota kecamatan dan ibukota Propinsi Sumatra Barat, namun 15 km dari pusat pemerintahan Kota Padang. Kelurahan Purus memiliki 68 Ha dengan jumlah penduduk sebanyak 6239 orang. ${ }^{17}$ Kawasan ini bertipologi pesisir 383.88 mdl dari permukaan laut. Tidak ada hutan, sawah, tanah kering, tanah basah dan perkebunan serta peternakan.

Hasil pengamatan ternyata penduduk Kelurahan Purus bermata pencaharian sebagai nelayan, pedagang ikan di tepi pantai, berdagang di tepat tinggal, pengering ikan, dan pekerjaan penjual makanan hasil laut keliling, serta penjual ikan basah keliling. Bahkan ada juga pekerja sebagai buruh pada rumah makan, OB hotel di tepi pantai, kerajinan besi, menjahit, dan satpam

\footnotetext{
${ }^{16}$ Profil Kelurahan Purus Tahun 2015. Koleksi Arsip Kantor Lurah Purus Kecamatan Padang Barat, Padang, Sumatra Barat Indonesia

${ }^{17}$ Profil Kelurahan Purus tahun 2016. Koleksi Arsip Kantor Lurah Purus Kecamatan Padang Barat, Padang, Sumatra Barat Indonesia
}

165 | Seminar Nasional Sejarah ke 4 Jurusan Pendidikan Sejarah Universitas Negeri Padang 
hotel. ${ }^{18}$ Akan tetapi data kelurahan menunjukkan Usia 18-56 tahun yang bekerja 1217 orang/ $18 \%$ dan tidak bekerja $1677 / 25 \%$. Selanjutnya usia sekolah yang tidak bersekolah dan berhenti sebanyak 2193 atau 32\%. Sementara tamat SMP dan SMA sebanyak 2053 atau 30\%. Seakan berat secara sosial. Namun keluarga prasejahtera hanya tercatat $18,4 \% .{ }^{19}$ Kelurahan Purus merupakan kawasan wisata pantai dengan sejumlah hotel dan rumah makan. Di Kelurahan Purus juga terdapat hotel, gedung perguruan tinggi disamping sebuah sekolah SMP dan 4 SD. Selain itu terdapat 3 mesjid dan 2 Mushola. Satu mesjid baru dibangun-megah.

\section{Mata Pencaharian Penduduk di Kawasan Wisata Purus}

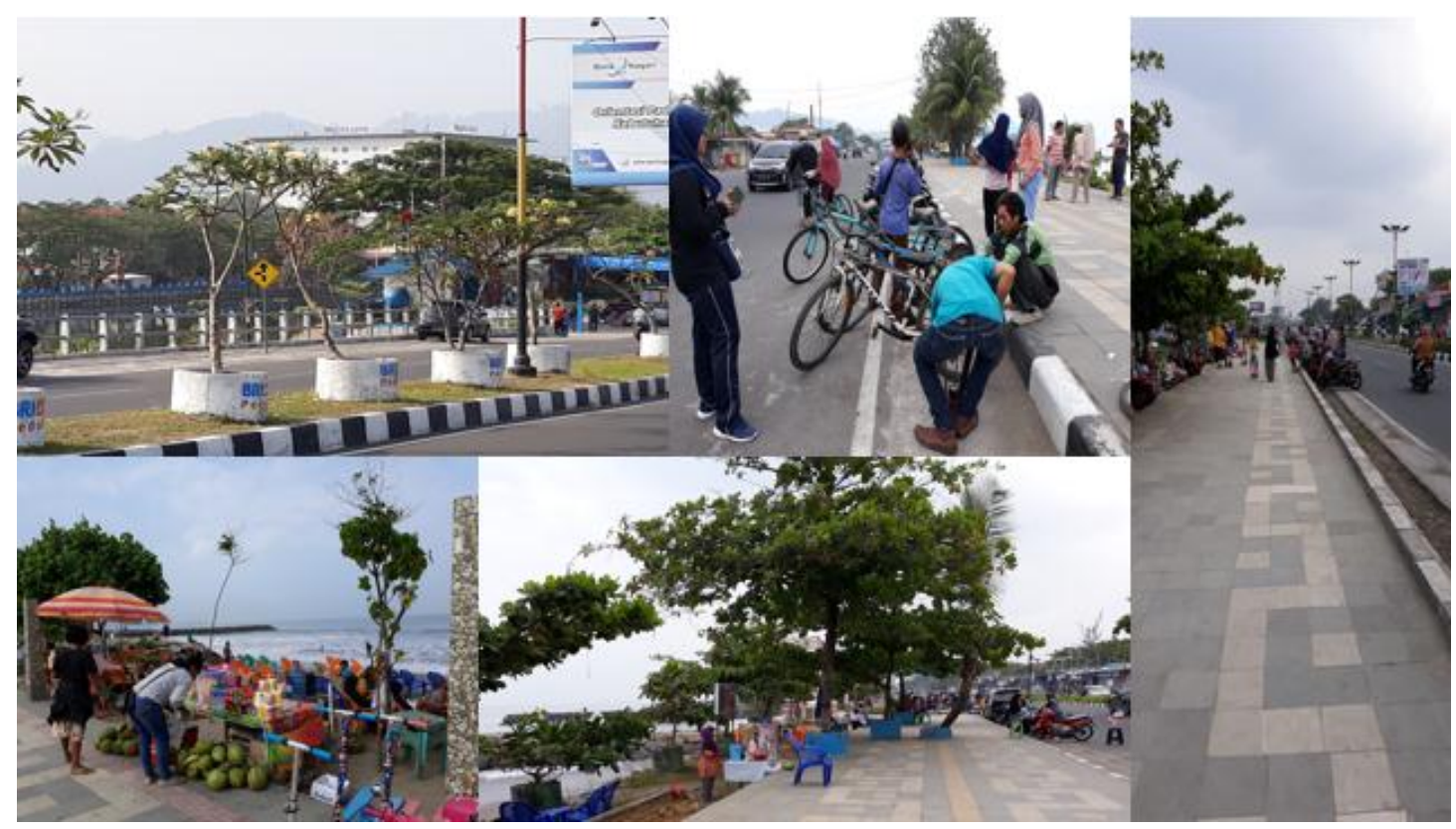

Sumber: Koleksi Pribadi Azmi Fitrisia, Purus Juli-Agustus 2019

Berdasarkan data diatas diketahui beratnya tantangan sosial di Kelurahan Purus. Penduduk usia kerja yang tidak bekerja, penduduk tidak bersekolah pada usia sekolah. Lebih-lebih jika kita perbandingkan dengan data kelurahan lain di Kecamatan Padang Barat, Purus terlihat paling

${ }^{18}$ Observasi Azmi Fitrisia, 2 Agustus 2018, 28 Juli 2019, wawancara dengan Ermita, di Kantor Lurah Purus, tanggal 21 September 2017, wawancara dengan Zurmailis di Purus III, tanggal 2 Agustus 2019.

${ }_{19}$ Profil Kelurahan Purus 2017. Koleksi Arsip Kantor Lurah Purus Kecamatan Padang Barat, Padang, Sumatra Barat Indonesia.

166 | Seminar Nasional Sejarah ke 4 Jurusan Pendidikan Sejarah Universitas Negeri Padang 
banyak penduduk prasejahtera dan sejahtera $\mathrm{I}^{20}$ Demi kiaan juga kasus kriminal tertinggi di kawasan ini terutama jamret dan pencurian alat dan motor. ${ }^{21}$ Hal ini mungkin karena kurang terkelolanya kekayaan di kelurahan. Masyarakat kelas menengah atas kurang perhatian. Pengalaman dalam pelaksanaan kegiatan pengabdian berturut turut tahun 2016, 2017, dan 2018 membuktikan sukarnya untuk menarik masyarakat menengah ke atas untuk berpartisipasi sebagai pembina dan memberi pekerjaan bagi masyarakat menengah ke bawah dalam bidang menjahit. Padahal mereka memiliki usaha jahit yang tergolong besar dan terkenal. ${ }^{22}$ Bukti lain juga tergambar seperti rendahnya jumlah hewan Qurban pada Hari Raya Idul Adha. ${ }^{23}$

\section{Rumah Susun dan Rumah Penduduk Kelurahan Purus}

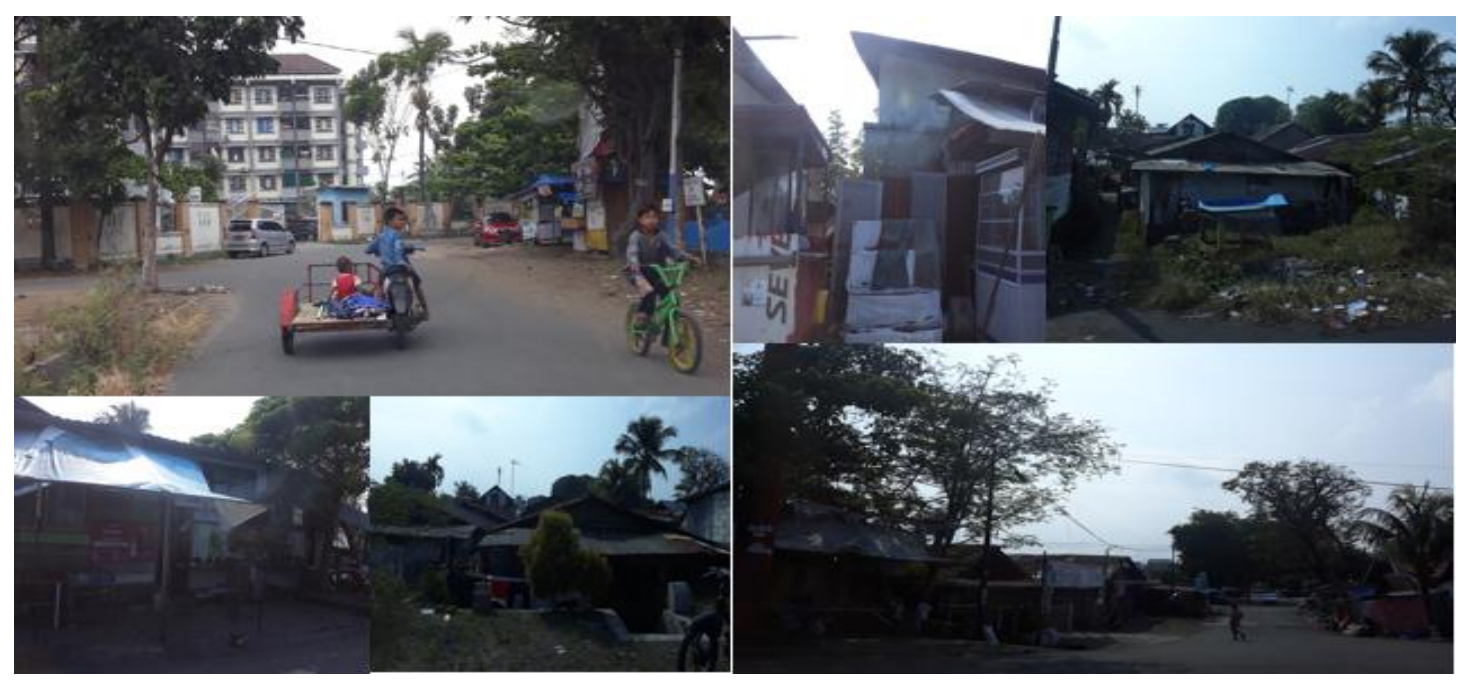

Sumber: Koleksi Pribadi Azmi Fitrisia, Purus Juli-Agusus 2019

Berkaitan dengan pesatnya arus globalisasi dan perkembangan teknologi yang semakin maju-revolusi industri 4.0 menuju 5.0 akan semakin menyeret masyarakat pesisir Purus ke arah ketidakberdayaan. Tingkat pendidikan yang masih rendah dan tingkat tidak bersekolah mencapai 32\% menjadi satu faktor terpinggirkannya masyarakat pesisir Purus. Masyarakat revolusi industri 4.0 menuntut keahlian dalam menghasilkan produk dengan dukungan teknologi. Padang, hlm. 65

${ }^{20}$ Tim BPS Kota Padang, 2016.Kecamatan Padang Barat dalam Angkan 2016. Padang: BPS Kota

21 Ibid, hlm 99.

22 Azmi Fitrisia, dkk. 2016. laporan Pengabdian Kursus menjahit Tingkat Dasar. Padang UNP., Azmi Fitrisia dan Abdul Salam, laporan Pengabdian Kursus Menjahit Tingkat mahir dan Peluang Memperoleh Pendapatan Perempuan Nelayan Kelurahan Purus. Padang: UNP., Azmi Fitrisia, Abdul Salam, Rahmuliani,2018. Pengembangan Desain dan Usaha Menjahit perempuan Nelayan Kelurahan Purus. Padang: UNP.

${ }^{23}$ Tim BPS Kota Padang, 2016, Op. Cit, hlm. 89 167 | Seminar Nasional Sejarah ke 4 Jurusan Pendidikan Sejarah Universitas Negeri Padang 
Demikian juga bidang pemasaran segalanya memanfaatkan teknologi. Dunia akan terhubung dalam ruang maya. Saat ini saja tingkat pengangguran sudah $25 \%$ dari jumlah penduduk. Penduduk prasejahtera dan sejahtera I juga hampir 1/5 penduduk Kelurahan Purus. Demikian juga masalah sosial ekonomi yang terdapat di kelurahan ini. Kemajuan teknologi yang akan menyeret masyarakat kepada ekonomi global. Pertukaran tenaga kerja dan penggunaan alat-alat rumah tangga seperti robot akan mengurangi penggunaan tenaga manusia apalagi masyarakat dengan pendidikan rendah. Mereka tidak bersekolah dengan sendirinya sukar bagi mereka beradaptasi pekerjaan yang menggunakan teknologi canggih. Hal ini akan mengakibatkan semakin tersisihnya masyarakat pesisir Purus. Revolusi industri 4.0 yang didukung oleh beberapa kesepakatan international seperti dalam hal tenaga kerja tentu akan berpengaruh dan menimbulkan persaingan yang semakin ketat antara tenaga kerja Indonesia dengan negaranegara asing. Dengan demikian pemerintah seharusnya mempersiapkan agar keterpurukan masyarakat pesisir tidak terjadi. Gerakan persamaan ijazah diperlukan bagi masyrakat nelayan Purus.

Seterusnya generasi muda Purus telah menggunakan teknologi maju terutama handphone android. Alat-alat lain yang mereka gunakan sebagai kebutuhan di rumah tangga adalah TV, radio, dan mesin cuci. Hal ini adalah alat-alat yang sudah dikenal akrab oleh masyarakat. Namun mereka memiliki sedikit pengetahuan mengenai alat-alat berteknologi canggih yang membantu memudahkan dalam bidang produksi dan pemasaran atau membantu dalam urusan rumah tangga. Bahkan mungkin mereka tidak menyadari ancaman dari perubahan global yang terjadi akibat revolusi industri. Ini wajar karena pandangan mereka hanya pada masalah yang ada dihadapan saja yaitu menyediakan kebutuhan sehari hari.

Anak-anak memperoleh handphone dari orang tua, keluarga dan usaha sendiri. ${ }^{24}$ Anak-anak kecil di pantai Purus pun pandai memegang handphone atau ipad karena diberikan orang tua. Handphone/ipad digunakan sebagai alat hiburan. Bagi orangtua asal anak diam diberikan mainan. Untuk lapang dan tenang ibu dalam bekerja maka handphone sebagai alternatif. ${ }^{25}$ Satu hal yang mengerikan karena fungsi handphone dan ipad tidak untuk tujuan pengembangan. Handphone telah menjadi familiar dengan dengan anak-anak pantai. Akan tetapi

\footnotetext{
${ }^{24}$ Wawancara dengan Rezi, Rachel, Dea di Purus III, tanggal 21 Juli 2019

${ }^{25}$ Wawancara dengan Hendri di Kelurahan Purus,tanggal 21 Juli 2019
} 168 | Seminar Nasional Sejarah ke 4 Jurusan Pendidikan Sejarah Universitas Negeri Padang 
permasalahannya adalah fungsi alat ini. Kebanyakan anak-anak pantai menggunakan handphone untuk komunikasi dan sarana hiburan. Bahkan mereka lebih banyak memanfaatkan alat ini untuk fungsi hiburan. Sulit untuk mengontrol apa yang dilihat oleh anak-anak pantai pada handphone. Karena orang tua mereka juga punya masalah dengan ekonomi mereka dan tidak memiliki pandangan yang kuat tentang bagaimana seharusnya masa depan anak anak mereka.

\section{Simpulan}

Arus 4.0 telah masuk ke ruang kehidupan anak-anak pantai Kelurahan Purus. Namun tidaklah berfungsi ekonomis sebaliknya lebih kepada dunia hiburan. Ada kecemasan anak-anak ekonomi menengah kewah ini akan semakin terpinggirkan dimasa yang akan datang. Hal ini karena tingginya tingkat putus sekolah anak usia sekolah. Pemerintah dan relawan sosial serta perguruan tinggi berusaha untuk memberikan ruang positif pada anak-anak pantai namun sangat terbatas yang mereka butuhkan. Kompleksitas masalah ekonomi telah memecah konsentrasi untuk mengangkat problem anak-anak Purus

\section{DAFTAR PUSTAKA}

Ahmad Fauzi, Ekonomi Perikanan:Teori Kebijakan dan Pengelolaan. Jakarta: Gramedia Pustaka Utaa, 2010

Arif Sritua, Pengantar Sosiologi Masyarakat Pesisir. .Jakarta: Kerjasana Ekologi Manusia IPB dengan Yayasan Pustaka Obor Indonesia, 2015.

Azmi Fitrisia, dkk. 2016. laporan Pengabdian Kursus menjahit Tingkat Dasar. Padang UNP., , Abdul Salam, laporan Pengabdian Kursus Menjahit Tingkat mahir dan Peluang Memperoleh Pendapatan Perempuan Nelayan Kelurahan Purus. Padang: UNP. , Abdul Salam, Rahmuliani,2018. Pengembangan Desain dan Usaha Menjahit perempuan Nelayan Kelurahan Purus. Padang: UNP.

Dian Saptarini, Suprapti, Happy Ratna Santosa, Pengelolaan Sumberdaya Kelautan dan Wilayah Pesisir. Jakarta: 1996. 
Elfindri, Ekonomi Patron -Client: Fenomena Mikro Rumah Tangga Nelayan dan Kebijakan Makro. Padang: Universitas Andals Press 2002

Firth, Raymond. Malay Fishermen Their Peasent Economy. (New York : W.E. Norton \& Company. INC, 1975,

Https://medium.com/@kastrat.himatekpal/revolusi-industri-4-0-di-sektor-mari

tim-asean-bb15b76d30ae. Diakses 1 Agustus 2019.

Https://www.tokohkita.co/read/20190214/187/ Diakases 1 Agustus 2019

Https://www.telkomsat.co.Id/id/berita/telkomsat-berpartisipasi-dalam-seminar-na. Daikases 1

Agustus 2019

Kusnadi, Akar Kemiskinan Nelayan. Yogyakarta: LKiS, 2003.

Mulyadi.S, Ekonomi Kelautan. Jakarta: Rajagrafindo Persada, 2005.

Mubyarto dan Kawan Kawan, Kemiskinan pada Masyarakat di Dua Desa Pantai. Jakarta: Sinar Harapan, 1984.

M. Zauwir Abdullah, Tri Sukirno Putro dan Syapsan, Pengaruh Kondisi Sosial Ekonomi terhadap Tingkat Pendidikan Anak-Anak Nelayan Kecamatan Mandah Kabupaten Indragiri Hilir, dalam jurnal Ekonomi Vol 25 No. 3, September 2017.

Nani Suryani, Siti Amanah, Yatri Indah Kusumastuti, Analisis Pendidikan Formal Anak pada Keluarga Nelayan Di Desa Kalangjaladri Kecamatan Parigi Kabupaten Ciamis Provinsi Jawa Barat. Dalam Buletin Ekonomi Perikanan.Vol. 5. No. 2, 2004

Nina Siti Salmaniah Siregar, Kesadaran Masyarakat Nelayan terhadap Pendidikan Anak. Dalam Jurnal Ilmu Pemerintahan dan Sosial Politik, Vol 4 No.1, 2016. hlm 1-10.

Observasi Azmi Fitrisia, 12 September 2016

Observasi Azmi Fitrisia, 5 September 2017

Observasi Azmi Fitrisia, 2 Agustus 2018,

Observasi Azmi Fitrisia, 28 Juli 2019

Observasi Azmi Fitrisia, 4 Agustus 2019

Profil Kelurahan Purus Tahun 2015. Koleksi Arsip Kantor Lurah Purus Kecamatan Padang Barat, Padang, Sumatra Barat Indonesia

Profil Kelurahan Purus tahun 2016. Koleksi Arsip Kantor Lurah Purus Kecamatan Padang Barat, Padang, Sumatra Barat Indonesia 
Pudji Purwanti, Model Ekonomi Rumah Tangga Nelayan Skala Kecil. Malang: Universitas Brawijaya Press, 2010.

Profil Kelurahan Purus 2017. Koleksi Arsip Kantor Lurah Purus Kecamatan Padang Barat, Padang, Sumatra Barat Indonesia.

Sajogyo dan Pujiwati Sajogyo, ed. Sosiologi Pedesaan. Yogyakarta: Gadjahmada University Press, 1983.

Tim BPS Kota Padang, 2016.Kecamatan Padang Barat dalam Angkan 2016. Padang: BPS Kota Padang.

Wawancara dengan Ermita, di kantor Lurah Purus, tanggal 21 September 2017

Wawancara dengan Rezi, di Purus III, tanggal 21 Juli 2019

Wawancara dengan Rachel di Purus III, tanggal 21 Juli 2019

Wawancara dengan Dea di Purus III, tanggal 21 Juli 2019

Wawancara dengan Hendri di Kelurahan Purus,tanggal 21 Juli 2019

Wawancara dengan Fajri, di Kantor Lurah Purus, tanggal 22 Juli 2019

Wawancara dengan Zurmailis di Purus III, tanggal 2 Agustus 2019 